\title{
Intra-articular distension and steroids in the management of capsulitis of the shoulder
}

Leo GH Jacobs, Margaret A J Barton, W Angus Wallace, John Ferrousis, Nigel A Dunn, David H Bossingham

\begin{abstract}
Objective-To determine whether there is any synergistic effect in the administration of intraarticular steroids with distension in the management of early capsulitis of the shoulder.
\end{abstract}

Design-Prospective randomised trial of three treatments - namely distension only, steroid only, and steroid with distension.

Setting-Academic department of orthopaedic and accident surgery at Queen's Medical Centre, Nottingham.

Subjects -47 patients ( 30 women) with capsulitis affecting 50 shoulders.

Interventions-Three intra-articular injections into the shoulder given at six week intervals by the same technique.

Main outcome measures-Passive range of abduction, forward flexion, and external rotation; results of shoulder dynamometry measuring work done and torque produced; pain levels at rest and with resisted movement.

Results-All patients reported improvement during the study. Analysis of the mean improvements in abduction and forward flexion showed these to be significantly greater in the steroid with distension and steroid only groups than in the distension only group (mean improvements in abduction (degrees/ week (95\% confidence interval)) $4.3(3.4$ to $5 \cdot 2$ ), $3.4(2.4$ to 4.5$)$, and $1.0(-0.8$ to 2.8$)$ in the three groups respectively; mean improvements in flexion (degrees/week (95\% confidence interval)) 3.6 (3.2 to $4 \cdot 0), 3 \cdot 3(2 \cdot 3$ to $4 \cdot 3)$, and $1 \cdot 5(0 \cdot 5$ to $2 \cdot 5)$ respectively). Shoulder dynamometry failed to show a significant difference among the treatment groups. No severe complications occurred as a result of the injections, but two patients reported facial flushing related to the use of steroids.

Conclusion-Intra-articular steroid injections have a useful role in the outpatient management of early capsulitis. Surgery, University Hospital, Queen's Medical Centre, Nottingham NG7 2UH

Leo G H Jacobs, FRCSED, research fellow

Margaret A J Barton, MCsP, research physiotherapist W Angus Wallace, FRCSED (ORTH), professor John Ferrousis, PI (University of Athens), research fellow

\section{Department of} Rheumatology, City Hospital, Nottingham Nigel A Dunn, MRCP, senior registrar in rheumatology David H Bossingham, FRCP, consultant rheumatologist

Correspondence to: Professor Wallace.

Capsulitis of the shoulder, or frozen shoulder, ' is an idiopathic condition unique to this joint. The condition was first described by Duplay in 1872, who called it périarthrite scapulo-humérale. ${ }^{2}$ In this paper we use the term capsulitis of the shoulder to refer to an idiopathic painful condition of the shoulder affecting all active and passive movements of the joint but whose main characteristic is grossly restricted external rotation. It has been shown to be a self limiting condition, ${ }^{3}$ passing through three phases, usually over 12-24 months. These phases were described by Rowe and Leffert as "freezing, frozen, and thawing." Uncommonly there may not be complete resolution of the shoulder stiffness in the long term. ${ }^{5.7}$ Nevertheless, as the mobility of the shoulder has been shown to diminish with age, ${ }^{8}$ probably in relation to decreased physical activity, ${ }^{9}$ this residual stiffness is often associated by the patient with normal aging and is rarely a cause of complaint.
Lee $e t$ al reported on the large variety of treatments for capsulitis and concluded: "The very diversity of these methods casts doubt on the efficacy of any."10

The use of hydrocortisone injections for capsulitis was first reported by Murnaghan and McIntosh." Hydrocortisone has now been replaced by newer, long acting insoluble derivatives in an attempt to prolong the anti-inflamatory effect and diminish systemic side effects. Published reports of the results of these injections indicated that there was little long term advantage with the use of steroid injections. ${ }^{1012} 13$ But no paper was clear with regard to the precise anatomical site of the injection, which would affect the results.

The use of hydraulic distension in capsulitis was described after arthrographic investigations showed adhesions and a decreased joint space. Some patients had a dramatic improvement in their shoulder symptoms 48 hours after arthrography. ${ }^{14}$ Reports evaluating this method of treatment described results after relatively large $(50 \mathrm{ml})$ intra-articular injections of saline. ${ }^{15} 16$ Wallace and Echeverri reported good results after intra-articular distension with an injection of steroid, local anaesthetic, and air (total volume $10 \mathrm{ml}$ ) in patients with capsulitis of the shoulder. ${ }^{17}$ We decided to investigate whether these good results were due to the action of the steroid alone or the distension alone or whether both intra-articular steroid and distension were required to obtain good results.

\section{Patients and methods}

Outpatients were referred by their general practitioners to a special clinic set up for this prospective randomised trial. Both shoulder girdles were fully assessed at the patient's initial visit, including a careful assessment of the cervical spine. Patients with diabetes mellitus or a myocardial infarction immediately before the onset of symptoms were excluded as these conditions may precipitate capsulitis and influence the patient's recovery. ${ }^{1218}$ Furthermore, two of us (WW and $\mathrm{DB}$ ) believed that capsulitis associated with these conditions was more resistant to treatment.

Entry into the study was based on the following criteria: abduction and forward flexion less than $90^{\circ}$; external rotation less than $20^{\circ}$; intact rotator cuff

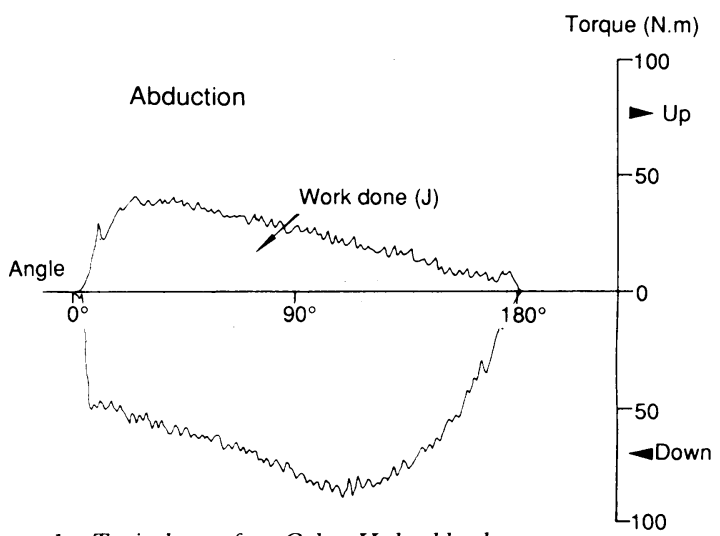

FIG 1-Typical trace from Cybex II shoulder dynamometer 


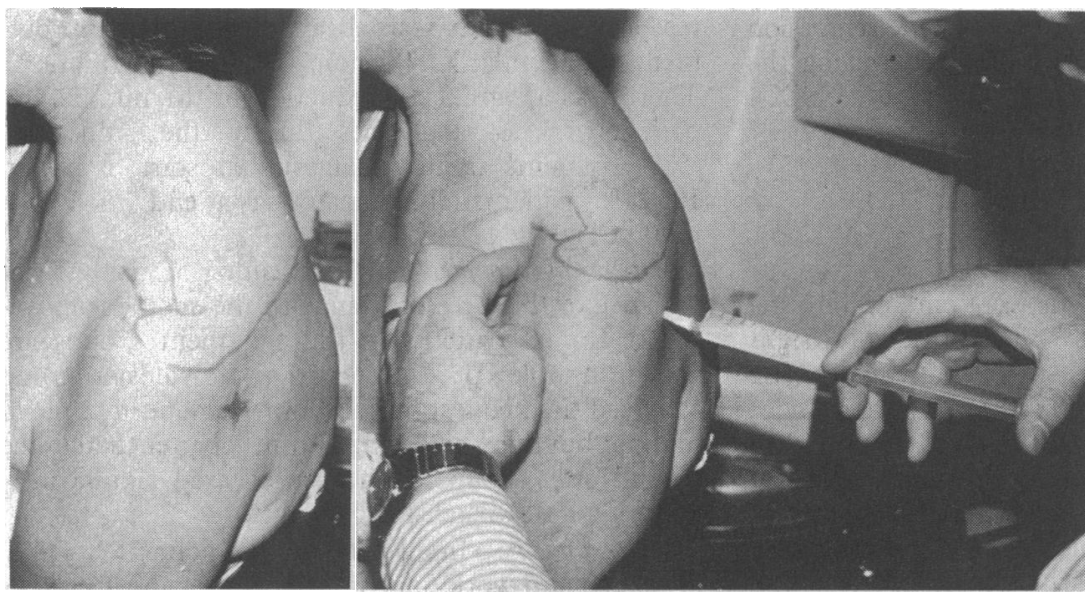

FIG 2 (left)-Bony landmarks outlined in preparation for injecting left shoulder by posterior approach FIG 3 (right)-Injection of steroid and local anaesthetic being given by posterior approach

clinically; normal shoulder radiographs. Patients were included regardless of the severity of pain when using the limb, at rest, or at night; a history of trauma; or the duration of symptoms. Active and passive abduction and forward flexion were measured with the patient standing upright against a wall and by using a hydrogoniometer (MIE Medical Research Ltd), and passive external rotation was measured with the elbow at $90^{\circ}$ as described by Cyriax. ${ }^{19}$ Rotator cuff integrity was established by testing the power of the supraspinatus, infraspinatus, and subscapularis muscles. Standing anteroposterior and axial radiographs of the affected shoulder were taken. Osteoporosis of the shoulder was not an exclusion criterion, but radiological evidence of rotator cuff disease was.

\section{ASSESSMENT}

Patients were assessed in two main ways - namely, clinically and by shoulder dynamometry.

\section{Clinical assessment}

All clinical assessments were performed blind and took place at the first visit and at six and 12 weeks. The assessors for the first three visits were $\mathrm{LJ}, \mathrm{JF}$, and ND, who performed $105(70 \%), 29(19 \%)$ and $16(11 \%)$ assessments respectively. WW performed a further blind assessment at 16 weeks on all patients entered into the study; 16 weeks was designated as the conclusion of the study and patients were then discharged.

At each visit the following details were recorded on a Cata sheet: $(a)$ the patient's analgesic use (assessed by type(s) of analgesic and number of tablets taken daily); (b) severity of pain in relation to daily activities (scored on a six ${ }^{1}$ point scale from 0 (none) to 5 (severe; interferes with sleep); (c) severity of pain with resisted shoulder movement (scored on a four point scale from 0 (none) to 3 (severe; with pain inhibition); (d) range of active and passive abduction, forward flexion, and external rotation of the shoulder.

\section{Shoulder dynamometry}

Patients were assessed at two week intervals with an isokinetic shoulder dynamometer built in the Nottingham University Hospital workshop and based on the Cybex II instrument. Dynamometry was supervised by $M B$, who was unaware of the treatment group to which each patient belonged. The method used was that described by Barton $e t a l^{20}$ and verified by Robinson. ${ }^{21}$ Both arms were assessed three times in abduction and in flexion with the dynamometer speed set at $60 \%$. The mean values of the following variables for each arm were calculated with a custom written computer program: $(a)$ work done in abduction; $(b)$ work done in flexion; $(c)$ torque produced at $90^{\circ}$ abduction; $(d)$ torque produced at $90^{\circ}$ flexion. Work done, measured in Joules $(\mathrm{J})$, was extrapolated from the area under the graph (fig 1 ). The torque produced at $90^{\circ}$ abduction and $90^{\circ}$ flexion was measured in newton meters (N.m) on the $x$ axis (fig 1 ).

\section{INTRA-ARTICULAR INJECTIONS}

Management of capsulitis was by intra-articular injections administered via the posterior approach as described by Cyriax and Russell. ${ }^{22}$ The technique of injections is as follows:

The patient is seated on a chair facing away from the operator. The posterior corner of the acromion is identified and a point on the skin $1 \mathrm{~cm}$ inferior to it marked with a cross using the thumb nail (fig 2 ). The area of skin marked with the cross is cleaned with an alcohol impregnated swab. The operator then places his or her non-dominant index or long finger on the coracoid process anteriorly and thumb on the posterior corner of the acromion. A syringe with a $40 \mathrm{~mm} 21$ gauge needle is held horizontally and inserted through the centre of the cross in the direction of the operator's finger on the coracoid process. Some resistance is felt as the capsule is pierced, and the patient usually complains of pain at that point. The needle is then stopped by the humeral head or passes between the head and the acromion process. If the humeral head is not encountered the operator should check the inclination of the needle in relation to the coracoid process. The injection is then given slowly (fig 3)

\section{TREATMENT GROUPS}

After their first assessment patients were prospectively randomised into three treatment groups stratified by sex. Patients who had bilateral capsulitis had each shoulder randomised separately. All injections were given immediately after assessments had been completed. All patients gave fully informed consent at the start of treatment.

The treatment groups were $(a)$ distension only group ( $6 \mathrm{ml} 0.25 \%$ bupivacaine $+3 \mathrm{ml}$ air; total volume $9 \mathrm{ml}$ ); (b) steroid only group (triamcinolone acetonide $(40 \mathrm{mg}$ ) alone; total volume $1 \mathrm{ml}$ ); (c) steroid and distension group (triamcinolone acetonide $(40 \mathrm{mg})+6 \mathrm{ml} 0 \cdot 25 \%$ bupivacaine $+3 \mathrm{ml}$ air; total volume $10 \mathrm{ml}$ ).

Each patient was offered a total of three injections at six week intervals unless they either refused or had a dramatically improved range of movement and no pain at all. Ethical approval could not be obtained for a "no injection" group, so that the distension only group served as controls (though we recognised that there may well be potential benefit from this form of treatment). All patients were given an information sheet with a home exercise programme which also explained capsulitis, and no patient was referred for hospital physiotherapy. Any patient could be withdrawn from the study if his or her clinical progress was unsatisfactory and after discussion with WW. Withdrawal meant that patients were given intra-articular injections with steroids and distension and were followed up using the same protocol in tandem with the study. All patients were required to attend at least eight times in order to complete the study.

\section{STATISTICAL ANALYSIS}

The passive ranges of abduction, flexion, and external rotation were used for analysis as suggested by Binder $e t a l$ and elsewhere. ${ }^{23}$ The changes in passive range of movements and dynamometer variables for all patients in the study (until they either completed the study or were withdrawn) were used in the analysis. Summary statistics from the slopes of individual regression lines were calculated for the rate of change in shoulder movements and shoulder dynamometer variables. This then allowed for one way analysis of 
variance of within patient differences of the regression slopes $^{24}$ for the three treatment groups by using the statistical package for the social sciences (SPSS-X). Other intergroup differences were analysed with the $\chi^{2}$ test (SPSS-X).

\section{Results}

Fifty shoulders of 47 patients were entered into the study over two years. The ratio of left to right shoulders affected was 3:2, three patients having bilateral capsulitis. Thirty (64\%) patients were women, and the non-dominant arm was affected in $30(60 \%)$ shoulders. Patients were first seen between one and 24 months after the onset of symptoms (median six months). No patient gave a history of a fractured arm.

Table I gives an analysis of the complete study group. Three patients defaulted at between four and eight weeks for reasons unconnected with the study. One other patient was unable to continue dynamometric assessment after 10 weeks because of a cerebrovascular accident. There was no significant difference among the treatment groups with regard to age, duration of symptoms, sex distribution, dominance, or occupation (table I). The numbers of patients withdrawn from the study because of poor clinical progress were five $(36 \%)$ from the distension only group, three $(20 \%)$ from the steroid only group, and none from the steroid and distension group.

Table II shows the improvement in symptoms in all patients in the study with regard to pain at

TABLE I-Distribution of 47 patients (50 affected shoulders) entered into study

\begin{tabular}{lccc}
\hline & \multicolumn{3}{c}{ Treatment group } \\
\cline { 2 - 4 } & $\begin{array}{c}\text { Distension only } \\
\text { (14 patients) }\end{array}$ & $\begin{array}{c}\text { Steroid only } \\
\text { (15 patients) }\end{array}$ & $\begin{array}{c}\text { Steroid and } \\
\text { distension } \\
\text { (18 patients) }\end{array}$ \\
\hline $\begin{array}{c}\text { Total shoulders } \\
\quad \text { No in men }\end{array}$ & 5 & 16 & 18 \\
$\quad$ No in women & 11 & 5 & 9 \\
$\begin{array}{c}\text { No of patients } \\
\text { defaulted }\end{array}$ & 2 & 11 & 9 \\
$\begin{array}{l}\text { Mean age (years) } \\
\text { Mean duration of } \\
\text { symptoms (months) }\end{array}$ & 53 & 52 & 0 \\
$\begin{array}{l}\text { Dominant side: } \\
\quad \text { Right }\end{array} \quad 6$ & 6 & 55 \\
$\quad \begin{array}{l}\text { Left } \\
\text { Occupation: }\end{array} \quad 14$ & 15 & 8 \\
$\quad \begin{array}{l}\text { Manual } \\
\text { Non-manual }\end{array}$ & 2 & 1 & 17 \\
\hline
\end{tabular}

TABLE II - Improvement in pain over study period in all patients at rest and all patients with resisted abduction

\begin{tabular}{llc}
\hline & \multicolumn{1}{c}{ No of patients } \\
\cline { 3 - 3 } Grade $\quad$ Degree of pain & At start of study $\begin{array}{c}\text { At end of study } \\
\text { (after 16 weeks) }\end{array}$ \\
\hline
\end{tabular}

\begin{tabular}{llrr}
\hline \multicolumn{2}{c}{ All patients at rest } \\
0 & None & 0 & 38 \\
1 & Slight or occassional & 10 & 5 \\
2 & After unusual activity & 6 & 2 \\
3 & Moderate (alters use) & 5 & 1 \\
4 & Marked (limits activity) & 5 & 1 \\
5 & Severe (loss of sleep) & 21 & 0 \\
\multicolumn{1}{c}{ All patients with resisted abduction } & \\
0 & None & 15 & 39 \\
1 & Mild (slight ache) & 24 & 4 \\
2 & Moderate(no pain inhibition) & 4 & 4 \\
3 & Severe (pain inhibition) & 4 & 0 \\
\hline
\end{tabular}

TABLE III-One way analysis of variance of between group differences for mean improvement in shoulder range of abduction, flexion, and external rotation over study period for three injection regimens ( 50 shoulders)

\begin{tabular}{|c|c|c|c|c|c|}
\hline \multirow[b]{2}{*}{ Movement } & \multicolumn{3}{|c|}{$\begin{array}{l}\text { Improvement in range of movement over } 16 \text { weeks } \\
(\mathrm{J} / \text { week }(95 \% \text { confidence interval }))\end{array}$} & \multirow[b]{2}{*}{$F$ value } & \multirow[b]{2}{*}{ p Valu } \\
\hline & Distension only & Steroid only & Steroid and distension & & \\
\hline Abduction & $1.0(-0.8$ to 2.8$)$ & $3.4(2.4$ to 4.5$)$ & $4 \cdot 3(3 \cdot 4$ to $5 \cdot 2)$ & 6.98 & $<0.01$ \\
\hline Flexion & $1.5(0.5$ to 2.5$)$ & $3.3(2.3$ to 4.3$)$ & $3.6(3.2$ to 4.0$)$ & 6.56 & $<0.01$ \\
\hline External rotation & $1 \cdot 2(0.3$ to $2 \cdot 2)$ & $1.7(1.2$ to 2.3$)$ & $2.1(1.6$ to 2.6$)$ & $2 \cdot 76$ & $>0.05$ \\
\hline
\end{tabular}

rest and pain with resisted abduction (the improvement was similar for flexion and external rotation). There was a significant reduction in the numbers of patients taking analgesics during the study (27 $(57 \%)$ patients taking analgesics at start of study; $10(21 \%)$ patients taking analgesics at end $\left(\chi^{2}=15 \cdot 64\right.$; $\mathrm{p}<0 \cdot 001)$ ).

Range of movement-The results of analysis of variance of the rates of change in the shoulder movements for all patients in the treatment groups are shown in table III. The steroid and distension group achieved the greatest overall improvement in range of motion, but this was not significantly better than in the steroid only group. Both groups fared significantly better than the distension only group.

Dynamometry - In all patients the moment (torque) produced and work done improved over the 16 weeks of the study. Analysis of the rate of change failed to detect any significant differences among the treatment groups (tables IV and V). The treatment groups also showed no differences when they were further subdivided by sex and dominance.

Complications - No patient developed intra-articular sepsis or a suprascapular nerve palsy after the intraarticular injections. Two patients, however, developed temporary $(<24$ hours $)$ facial flushing after their steroid injection. This was also reported by Pattrick and Docherty, ${ }^{25}$ but the mechanism remains unclear. The cerebrovascular accident in one patient was thought to be unrelated to the intra-articular steroid injections.

\section{Discussion}

All patients entered into this study improved during treatment as was shown by their decreased analgesic consumption and the improvement in painful symptoms. The relief of symptoms was not confined to any specific treatment group, so that intra-articular distension of a shoulder affected by capsulitis cannot be said to be placebo treatment. Table III shows that there was a significantly increased rate of improvement in passive shoulder abduction and forward flexion in the two groups of patients treated with intra-articular steroid injections. The mean improvement was greatest in the steroid and distension group. That external rotation did not follow this pattern may in part reflect inaccuracy in our method of measuring this movement.

Pain is difficult to assess and is often an inaccurate outcome measure. We found no significant difference among the three treatment groups in their degree of pain (table II) or use of analgesics over the study period. Anticipating this result, we tried to use a more objective and quantifiable shoulder assessment system by making dynamometric measurements of patients' shoulders. The readings, however, seem to have been influenced by many other factors, such as pain, motivation, minor illnesses, etc. Thus there was a large scatter of results leading to poor reproducibility in these patients.

Reliable intra-articular injection into the shoulder may be difficult (D S Barrett, S A Copeland, paper presented at second scientific meeting of British Elbow and Shoulder Society, March, 1990). The intraarticular injection of a small volume of steroid into the shoulder may be less reliable than when a larger volume containing air is injected. Air in the shoulder results in a "squelch" when the joint is subsequently moved. This was found after all 59 intra-articular shoulder injections performed personally by $\mathrm{LJ}$ in which air was a component. An air arthrogram can be obtained after injection but it was not possible to obtain ethical approval for this additional radiographic examination.

Manipulation of the shoulder under general 
TABLE IV-One way analysis of variance of between group differences for mean improvement in work done for shoulder abduction and flexion over study period for three injection regimens (50 shoulders)

\begin{tabular}{|c|c|c|c|c|c|}
\hline \multirow[b]{2}{*}{ Movement } & \multicolumn{3}{|c|}{$\begin{array}{l}\text { Improvement in work done over } 16 \text { weeks } \\
(\mathrm{J} / \text { week }(95 \% \text { confidence interval }))\end{array}$} & \multirow[b]{2}{*}{$F$ value } & \multirow[b]{2}{*}{ p Value } \\
\hline & Distension only & Steroid only & Steroid and distension & & \\
\hline Abduction & $0.4(0.1$ to 0.7$)$ & $0.8(0.4$ to 1.2$)$ & $0.9(0.6$ to 1.7$)$ & 1.92 & $>0.05$ \\
\hline Flexion & $0.7(0.3$ to 1.1$)$ & $1.0(0.4$ to 1.6$)$ & $0.9(0.5$ to 1.4$)$ & 0.56 & $>0.05$ \\
\hline
\end{tabular}

TABLE $\mathrm{V}-$ One way analysis of variance of between group differences for mean improvement in torque produced for shoulder abduction and flexion over study period for three injection regimens ( 50 shoulders)

\begin{tabular}{|c|c|c|c|c|c|}
\hline \multirow[b]{2}{*}{ Movement } & \multicolumn{3}{|c|}{$\begin{array}{l}\text { Improvement in torque over } 16 \text { weeks } \\
(\mathrm{N} . \mathrm{m} / \text { week }(95 \% \text { confidence interval }))\end{array}$} & \multirow[b]{2}{*}{$F$ value } & \multirow[b]{2}{*}{ p Value } \\
\hline & Distension only & Steroid only & Steroid and distension & & \\
\hline Abduction & $0.3(0.0$ to 0.6$)$ & $0.5(0.2$ to 0.9$)$ & $0.6(0.1$ to 1.2$)$ & $1 \cdot 29$ & $>0.05$ \\
\hline Flexion & $0.6(0.3$ to 0.9$)$ & $0 \cdot 7(0 \cdot 3$ to $1 \cdot 1)$ & $0.7(0.5$ to 0.8$)$ & 0.01 & $>0.05$ \\
\hline
\end{tabular}
anaesthetic injection has been recommended for capsulitis. ${ }^{26}{ }^{27}$ This requires a more costly inpatient stay with general anaesthesia and immediate postoperative physiotherapy. There are also the risks of fracture of the humeral neck and rupture of the rotator cuff when the procedure is performed by an inexperienced surgeon. Our study indicates a positive role for intraarticular steroid injections in the early outpatient management of capsulitis of the shoulder.

We thank Lederle Laboratories (Cyanamid of Great Britain Ltd) and Astra Pharmaceuticals for funding part of this study. We also thank Mrs M Tew and Dr J Pearson for statistical advice when preparing this paper and the Audiovisual department, University Hospital, Queen's Medical Centre, Nottingham, for help with the illustrations.

I Codman EA. The shoulder. Boston: Thomas Todd, 1934

2 Duplay ES. De la périarthrite scapulo-humérale et des raideurs de l'epaule qui en sont la consequences. Archives Générales de Médecine 1872;20:513-42

Grey RG. The natural history of "idiopathic" frozen shoulder. I Bone foint Surg 1978;60A:56

4 Rowe CR, Leffert RD. Idiopathic chronic adhesive capsulitis ("frozen houlder" In: Rowe CR, ed The shoulder. New York: Churchill Living. tone, 1988:155-63.

5 Simmonds FA. Shoulder pain with particular reference to the "frozen shoulder." F Bone foint Surg 1949;31B:426-32.

6 Reeves B. The natural history of the frozen shoulder syndrome. Scand $f$ Rheumatol 1975; 4: 193-6.

7 Binder Al, Bulgen DY, Hazleman BL, Roberts S. Frozen shoulder: a longterm prospective study. Ann Rheum Dis 1984;43:361-4.

8 Bassey EJ, Morgan K, Dallosso HM, Ebrahim SBJ. Flexibility of the shoulder joint measured as range of abduction in a large representative sample of men and women over 65 years of age. Eur 7 Appl Physiol 1989;58:353-60.

9 Germain NW, Blair SN. Variability of shoulder flexion with age, activity and sex. Am Correct Ther f 1983:37 (6):156-60.

10 Lee PN, Lee M, Haq AMMM, Longton EB, Wright V. Periarthritis of the shoulder; trial of treatments investigated by multivariate analysis. $A n n$ Rheum Dis 1974:33:116-9.

11 Murnaghan GF, McIntosh D. Hydrocortisone in painful shoulder - a controlled trial. Lancet 1955;ii:798-800.

12 Bulgen DY, Binder AI, Hazleman BL, Dutton J, Roberts S. Frozen shoulder: prospective clinical study with an evaluation of three treatment regimens. Ann Rheum Dis 1984;43:353-60

13 Dacre JE, Beeney N, Scott DL. Injections and physiotherapy for the painful stiff shoulder. Ann Rheum Dis 1989;48:322-5.

14 Andrén L, Lundberg BJ. Treatment of rigid shoulder by joint distension during arthrography. Acta Orthop Scand 1965;36:45-53.

15 Older MWJ. Distension arthrography of the shoulder joint. In: Bayley I, Kessel L, eds. Shoulder surgerv. Berlin: Springer-Verlag, 1982:123-7.

16 Fareed DO, Gallivan WR. Office management of frozen shoulder syndrome. Clin Orthop 1989;242:177-83.

17 Wallace WA, Echeverri A. Intra-articular distension with local anaesthetic, steroid and air in the treatment of capsulitis of the shoulder. In: Proceedings of third international conference of surgery of the shoulder. Tokyo: Professional Postgraduate Services, 1987:204-8

18 Frozen shoulder [editorial]. N Z Med 7 1985:98:1039-40.

19 Cyriax J. Textbook of orthopaedic medicine. Vol 1. 6th ed. London: Baillière Tindall, 1975:229-43.

20 Barton MAJ, Wallace WA, Johnson F. Clinically useful measures of shoulder strength. In: Copeland $\mathrm{K}$ ed. Progress reports on electronics in medicine and biology. London: Institutition of Electronic and Radio Engineers, 1986: 185-92.

21 Robinson ND. An assessment of the benefits of local steroid injection in the treatment of painful arc syndrome of the shoulder (dissertation). Nottingham: University of Nottingham, 1987.

22 Crriax J, Russell G. Textbook of orthopaedic medicine. Vol 2. 9th ed. London: Baillière Tindall, 1977:164-6.

23 Frozen shoulder [editorial]. Lancet 1985;i:87-8.

24 Mattews JNS, Altman DG, Campbell J, Royson P. Analysis of serial measurements in medical research. BMF 1990;300:230-5.

25 Patrick $M$, Docherty $M$. Facial flushing after intra-articular injection of steroid. BMF 1987;295:1380.

26 Haines JF, Hargadon EJ. Manipulation as the primary treatment of the frozen shoulder. F R Coll Surg Edinb 1982;27 (5):271-5.

27 Bayley JIL, Kessel L. Treatment of the frozen shoulder by manipulation: a pilot study. In: Rowe CR, ed. The shoulder. New York: Churchill Livingstone, 1988: 118-23.

(Accepted 25 April 1991)

\title{
Impact of variability among surgeons on postoperative morbidity and mortality and ultimate survival
}

\author{
C S McArdle, D Hole
}

\section{Abstract}

Objective-To assess the differences among surgeons in postoperative complications, postoperative mortality, and survival in patients undergoing surgery for colorectal cancer.

Design-Prospective study of patients with colorectal cancer managed by one of 13 consultant surgeons, none of whom had a special interest in colorectal surgery.

Setting-Royal Infirmary, Glasgow.

University Department of Surgery, Royal Infirmary, Glasgow G31 2ER

C S McArdle, FRCS

consultant surgeon

Cancer Surveillance Unit, Ruchill Hospital, Glasgow G20

D Hole, MSC, senior

statistician

Correspondence to:

Mr McArdle.

BMF 1991;302:1501-5
Patients-645 sequential patients with colorectal cancer presenting over the six years from 1974 to 1979.

Main outcome measures-Postoperative complications, postoperative mortality (within $\mathbf{3 0}$ days), and survival (up to 10 years); predictive factors for postoperative mortality and survival; and relative hazard rate ratios for individual surgeons.

Results - The proportion of patients undergoing apparently curative resection varied among surgeons from $40 \%$ to $76 \%$; overall postoperative mortality varied from $8 \%$ to $30 \%$. After curative resection postoperative mortality varied from $0 \%$ to $20 \%$, local recurrence from $0 \%$ to $21 \%$, and the rate of anastomotic leak from $0 \%$ to $25 \%$. Survival at 10 years in patients who underwent curative resection varied from $20 \%$ to $63 \%$, two year survival in those who underwent palliative resection varied from $7 \%$ to $32 \%$, and median survival in those who underwent palliative diversion varied from one to eight months. The hazard rate ratios among individual surgeons, taking into account the identified risk factors, varied from 0.56 to 2.03 , from 0.17 to 1.92 , and from 0.57 to 1.50 for curative resection, palliative resection, and palliative diversion, respectively.

Conclusion-There were significant variations in patient outcome among surgeons after surgery for colorectal cancer; such differences compromise survival. A considerable improvement in overall survival might be achieved if such surgery were undertaken by surgeons with a special interest in colorectal surgery or surgical oncology.

\section{Introduction}

Previous studies have drawn attention to the extent of the intersurgeon variability in surgery for colorectal cancer. ${ }^{12}$ Differences in surgeon related variables, 